\title{
As mulheres do açaí: um estudo de caso acerca do trabalho feminino na Ilha de Guajará de Baixo, Cametá (PA)
}

\section{Açaí women: a case study about women's work in Guajará de Baixo Island, Cametá (PA)}

Renato dos Prazeres Rodrigues - Especialista em Agroecologia pelo Instituto Federal do Pará (IFPA) e em Sistemas Agroflorestais pela Universidade Federal do Pará (UFPA). E-mail: renatoadp13.rr@gmail.com

Monique Medeiros - Doutora em Agroecossistemas pela Universidade Federal de Santa Catarina (UFSC). Professora e Pesquisadora no Programa de Pós-Graduação em Agriculturas Amazônicas (PPGAA) da Universidade Federal do Pará (UFPA). E-mail: mmedeiros@ufpa.br

Aldrin Mário da Silva Benjamin - Doutor em Fitotecnia pela Universidade Federal Rural do Semiárido (UFERSA). Professor do Instituto Federal do Pará (IFPA). E-mail: aldrin. benjamin@ifpa.edu.br

\section{Resumo}

Dentre as diversas atividades desempenhadas pelas mulheres ribeirinhas em Cametá, Pará, é na produção do açaí que elas concentram grande parte da força de trabalho para a formação da renda familiar. Entretanto, esse trabalho feminino, a muitos olhares alheios, ainda é visto apenas como uma ajuda. Compreendendo a problemática atrelada à invisibilização do papel das mulheres nesse contexto, o objetivo deste trabalho foi analisar as atividades praticadas pelas mulheres da Ilha Guajará de Baixo, tanto no âmbito reprodutivo quanto produtivo, com principal atenção àquelas relacionadas ao açaí. Para a efetivação deste trabalho, foram realizadas, em maio de 2018 e julho de 2021, entrevistas semiestruturadas com 28 mulheres. Como resultado da pesquisa, identificou-se que essas mulheres possuem papel relevante não somente no cuidado da família, no âmbito doméstico, como também no desenvolvimento de atividades produtivas voltadas, sobretudo, ao açaí.

\section{Palavras-chave}

Mulheres ribeirinhas. Extrativismo do açaí. Invisibilização do trabalho feminino. Amazônia Paraense.

\begin{abstract}
Among the various activities performed by riverine women in Cametá, Pará, it is in the production of açaí that they concentrate much of their labor force for the formation of family income. However, this feminine work, to many outsiders, is still seen only as a help. Understanding the problem linked to the invisibilization of the role of women in this context, the objective of this work was to analyze the activities practiced by women from the Guajará de Baixo Island, both reproductively and productively, with special attention to those related to the açaí. To carry out this work, semistructured interviews were conducted with 28 women in May 2018 and July 2021. As a result of the research, it was identified that these women have a relevant role not only in caring for the family, in the domestic sphere, but also in the development of productive activities focused, above all, on açaí.
\end{abstract}

\section{Keywords}

Riverside women. Açaí extractivism. Invisibilization of women's work. Paraense Amazon. 


\section{INTRODUÇÃO}

O município paraense de Cametá é dividido em dois grandes ecossistemas com aptidão ao cultivo agrícola, estes são terra firme e várzea, que, respectivamente, implicam 17,1\% e 26,2\% do território. Aproximadamente 100 ilhas, que são consideradas várzeas, compõem Cametá e estão dispostas ao longo do rio Tocantins e de seus afluentes (OLIVEIRA; BRANDÃO; PENA, 2014). Os ecossistemas de várzeas, que são predominantes nas regiões das ilhas, sofrem inundações eventuais devido ao fluxo da maré alta/enchente que eleva o nível da água e banha o solo, depositando sedimentos que são absorvidos pelos vegetais em forma de nutrientes. Nesse estuário, as atividades extrativistas vegetal e animal predominam, tornando-se fonte importante na aquisição de alimento e renda das famílias.

Alguns estudos sobre o município de Cametá demonstram que 60\% da economia local provêm da agricultura, com destaque para o cultivo da mandioca (Manihot esculenta Crantz), a qual predomina em área de terra firme, e do extrativismo do açaí (Euterpe oleracea Mart.), vinculado às áreas de várzea (COSTA, 2010). Os açaizeiros apresentam-se de forma abundante no estuário ribeirinho cametaense e destacam-se pela sua importância como fonte alimentar e econômica (BATISTA, 2013; BATISTA; SANTANA; LEMOS, 2016).

Essa atividade agroextrativista é a mais influente nas várzeas do município de Cametá, segundo maior produtor do fruto no estado do Pará. Nos anos de 2018/2019, o agroextrativismo do açaí representou 51\% da produção agrícola municipal, o equivalente a 159.450 toneladas do fruto (IBGE, 2019).

Em consequência do exposto, cooperativas e empresas externas adentraram na cadeia de comercialização local para a compra da produção, levando muitas famílias ribeirinhas a se dedicarem diariamente ao manejo dos açaizais. A partir daí, as estratégias de produção e organização das divisões de trabalho na cadeia produtiva do açaí têm sido constantes e envolvem basicamente toda a família.

Diante desse contexto, estudos apontam que as mulheres assumem papel primordial na produção do açaí, pois participam diretamente de todas as etapas da cadeia, desde o manejo à venda do fruto. Sobre isto, Silva e Simonian (2006) afirmam que as mulheres do estuário amazônico executam as mais diversificadas funções, dentre elas, a pesca realizada em pequena escala, a manutenção dos apetrechos de pesca, o zelo pelos filhos e os afazeres no lar. Ademais, Burg e Lavato (2007) reconhecem que o trabalho realizado pela mulher constitui uma gama diversificada de funções que favorecem a unidade produtiva. 
No entanto, o trabalho das mulheres na agricultura é ainda menosprezado e não reconhecido, o que vem se consolidando ao longo da história de um meio rural patriarcal. E, de forma reativa, no atual contexto, as mulheres vêm lutando pela valorização dos seus trabalhos na agricultura (GEORGIN et al., 2015). Corroborando a importância dessa luta, este trabalho apresenta como objetivo analisar as atividades praticadas pelas mulheres da Ilha Guajará de Baixo, Cametá (PA), tanto no âmbito reprodutivo quanto produtivo, com principal atenção àquelas relacionadas ao açaí.

Dentre os principais resultados encontrados nessa pesquisa, destaca-se o relativo às mulheres de Guajará de Baixo possuírem papel relevante não somente no cuidado da família, no âmbito doméstico, como também no desenvolvimento de atividades produtivas relevantes à segurança alimentar e à garantia de renda de seus núcleos familiares.

\section{A INVISIBILIZAÇÃO DO TRABALHO FEMININO NO CAMPO}

Para Schneider (2001), na agricultura familiar, a pluriatividade envolve todo o núcleo familiar nas mais diversificadas funções. Estrategicamente, o chefe da família planeja, organiza e distribui os afazeres das etapas produtivas para cada membro do núcleo familiar (ROCHA, 2019). Segundo Schmitz e Santos (2013), na maioria dos estabelecimentos no meio rural, o homem assume a responsabilidade de chefe da família, excluindo os demais membros familiares da tomada de decisão, inclusive a mulher (esposa), protagonista diariamente em jornadas múltiplas de trabalho.

De acordo com Herrera (2013) e Santos, Bohn e Almeida (2020), as mulheres agricultoras, além da responsabilidade quase que exclusiva no trabalho reprodutivo, associado às funções domésticas e maternas, também realizam trabalho produtivo, estes fortemente ligados à agricultura. Segundo Silva e Steward (2020, p. 2): "para entender as relações de trabalho, compreende-se as atividades realizadas pelas mulheres que vão além dos espaços domésticos como as roças, o artesanato, o extrativismo, a criação de animais, cultivo de plantas medicinais entre outros".

No contexto amazônico, Faria e Nobre (1997) e Silva e Simonian (2006) descrevem a relação de gênero em uma comunidade ribeirinha marcada pela cultura do patriarcado. Nesse tipo de cultura, o trabalho praticado pelo gênero feminino é reconhecido como "ajuda" e pejorativamente visto como "coisinha leve" ou "coisinha pouca", marcado pela "invisibilidade" diante do gênero masculino, que ocupa o centro da "visibilidade" e das tomadas de decisões no estabelecimento. 
Segundo Rocha (2019), essa relação de invisibilidade do trabalho feminino se consolida além do processo produtivo na agricultura. Simonian (2006) destaca a invisibilidade do trabalho feminino na atividade de pesca, na comercialização, nas tomadas de decisões, na participação da renda familiar, no trabalho doméstico etc., mesmo sendo as atividades praticadas pelas mulheres primordiais para a consolidação da família no estuário do Baixo Tocantins. $\mathrm{Na}$ atividade agroextrativista do açaí, a invisibilização do trabalho produtivo da mulher ribeirinha se dá no que se refere tanto à composição da renda familiar quanto às práticas produtivas (SANTANA; PESSOA; SANTANA, 2012).

Para Santos, Bohn e Almeida (2020, p. 7), "ao não receber uma contrapartida financeira, [o trabalho da mulher] se torna invisibilizado na agricultura familiar, além de não possuir uma identidade e nem ter suas tarefas reconhecidas". Com base nessas percepções da condição da mulher no meio rural, a desigualdade de gênero inicia, desde muito cedo, na fase adolescente: o menino é "ajudante" do pai e a menina, da mãe (SILVA, 2019). Para Nobre (1998, p. 5):

Quando resgatamos, em uma linha da vida, o desenvolvimento de meninos e meninas, percebemos que, na área rural, eles estão juntos, sem grandes diferenças até por volta dos 5 anos. Depois, as meninas começam a seguir as mães, aprendendo com elas o trabalho doméstico e contribuindo para a realização deste. Os meninos passam a seguir o pai, a aprender com ele e a brincar entre meninos nas horas de lazer que geralmente são maiores que as das meninas. Os rapazes também saem mais, vão mais longe, enquanto as moças ficam mais com a família, não só pelo trabalho, mas pelo medo dos pais de que elas "caiam na vida".

Para Silva e Schneider (2010), essa divisão filho/filha, homem/mulher, impregnada no contexto rural, tende a se perpetuar na visibilidade do trabalho. Os filhos seguem os passos dos pais e são vistos como provedores. As filhas acompanham os passos das mães, envolvendo-se nos afazeres domésticos e agrícolas, os quais são percebidos como "ajuda". E assim, a desigualdade vai se espraiando ao passo que o trabalho reprodutivo das mulheres não é reconhecido pelo marido, pelos filhos, pelos vizinhos, pela sociedade como um todo (SILVA; STEWARD, 2020).

Para Brumer (2004), quando casadas, essas filhas também são subordinadas a esta situação, não mais vistas como ajudantes do pai mas, como ajudantes do marido (GORES, 2015). Assim sendo, essa situação se perpetua na dinâmica do trabalho na agricultura no decorrer do contexto histórico.

Ressalta-se que a presença da mulher agricultora no estabelecimento familiar tem sua importância além da execução do trabalho, pois são detentoras 
de saberes e práticas contextualizados são repassados para os filhos (SILVA; STEWARD, 2020). Segundo Rodrigues, Andrade, Silva e Nascimento (2015), as mulheres ribeirinhas:

[...] constituem elemento chave como detentoras de um conhecimento específico, ao mesmo tempo em que sustentam a forma de organização familiar e comunitária, não só no âmbito do saber-fazer, mas, sobretudo de preservação da cultura imaterial existente nestes contextos, tendo em vista que são elas as "guardiãs" e principais responsáveis pela transmissão e/ou ensino destes conhecimentos/saberes para as gerações presentes e futuras (RODRIGUES; ANDRADE; SILVA; NASCIMENTO, 2015, p. 4).

$\mathrm{Na}$ pesquisa de Amaral (2016), no Baixo Tocantins, contatou-se a importância do trabalho artesanal das mulheres na confecção de utensílios, como cuias, cestos, paneiros e abanos que são produzidos pelas mulheres. Ademais, atuam na extração do açaí enquanto fruto, no preparo do suco deste fruto, na criação de xerimbabos $^{1}$, na coleta de cacau, na extração do látex, entre outras atividades. Todas essas práticas formam o complexo de afazeres das mulheres ribeirinhas, que também se tornam elementos de identidade e resiliência (BATISTA, 2010).

\section{ESCOLHAS METODOLÓGICAS}

O estudo foi realizado na comunidade da Ilha de Guajará de Baixo, localizada à margem direita do rio Tocantins, em Cametá. A comunidade é distante $13 \mathrm{~km}$ da sede do município, com acesso por via fluvial, tendo o ecossistema de várzea como predominante nessa comunidade.

Em levantamento populacional realizado pelos autores, em 2020, junto às Agentes Comunitárias de Saúde (ACS) da localidade, constatou-se que a Ilha apresenta uma população estimada de 83 famílias e 395 habitantes, constituída por $54 \%$ do gênero masculino e $46 \%$ de gênero feminino. Desses, 38\% são adultos (35 a 60 anos); 20\% jovens adultos (18 a 35 anos); 19\% adolescentes (12 a 18 anos); 13\% crianças (até 11 anos) e 10\% idosos (60 anos em diante). Quanto à escolaridade, $56 \%$ frequentaram somente o ensino fundamental; $24 \%$ o ensino médio; $12 \%$ não estudaram, e $8 \%$ têm o nível superior.

Para a construção e a realização da análise de dados nesse e acerca desse contexto, optou-se pela modalidade de estudo de caso (GIL, 2008). O estudo mescla instrumentais quali e quantitativos (CRESWELL, 2007), obtidos por

\footnotetext{
Animais de pequeno porte (pato, galinha, peru, suínos) que se destinam principalmente ao autoconsumo e que podem ser comercializados eventualmente.
} 
meio da realização de questionários e entrevistas semiestruturadas direcionados às mulheres agricultoras da Ilha de Guajará de Baixo. Do total das 83 famílias existentes na comunidade, foram envolvidas na pesquisa 28 mulheres, casadas ou amasiadas, e uma viúva, que representaram 37\% das famílias locais.

Para se chegar às entrevistadas, recorreu-se à liderança da comunidade a qual apontou os sujeitos de maiores relevâncias na comunidade, tais como lideranças religiosas, parteiras, amassadoras de açaí, curandeiras, puxadoras ${ }^{2}$ e extratoras de óleo de andiroba, que também foram indicando outras mulheres. Ademais, vale mencionar que, para conseguir-se realizar as entrevistas diretamente com as mulheres, foi preciso, primeiramente, criar um vínculo de aproximação e confiança entre os pesquisadores e as pessoas indicadas como "chefes das famílias", que, no contexto local, eram todas do gênero masculino. Esses chefes de família eram quem autorizava a realização da pesquisa e a operacionalização das entrevistas nos seus estabelecimentos, propondo dias e horários oportunos para isso.

A pesquisa de campo deu-se durante todo o mês de maio de 2018. Os dados quantitativos foram atualizados, em contato com as informantes-chave em julho de 2021. As falas das mulheres foram anotadas e gravadas e, posteriormente, transcritas. Os dados foram sistematizados em tabelas e gráficos. Ademais, trechos das falas das entrevistadas foram analisados à luz da Análise do Discurso do Sujeito Coletivo (DSC) (LEFEVRE; LEFEVRE, 2003). Nessa análise, priorizouse manter a originalidade da fala das mulheres, para preservar a expressão cultural e histórica dos sujeitos participantes da pesquisa. Vale mencionar que todas as entrevistadas autorizaram a transcrição de seus depoimentos, bem como sua análise nessa pesquisa.

\section{A RELEVÂNCIA DAS MULHERES NA ILHA DE GUAJARÁ DE BAIXO: DA REPRODUÇÃO SOCIOCULTURAL À PRODUÇÃO DE ALIMENTOS E RENDA}

O processo de ocupação da Ilha de Guajará de Baixo deu-se ao longo do tempo de forma livre e espontânea. Em 2009, foi concedido pela Superintendência do Patrimônio da União do Estado do Pará (SPU/PA) o termo de autorização para a prática de atividades agroextrativistas. Cada família possui em média cinco hectares de terra, que são destinados para a construção do estabelecimento e realização de atividades agroextrativistas.

2 Mulheres especialistas na realização de massagens, nas quais é utilizado o óleo de andiroba, com vistas a diminuir dores e desconfortos causados por lesões musculares. 
A base produtiva familiar é ligada ao extrativismo, voltada para a coleta de sementes das oleaginosas andiroba (Carapa guianensis Aubl.) e ucuuba (Virola surinamensis (Rol.) Warb), amêndoas de cacau (Theobroma cacao L), buriti (Mauritia flexuosa L), coleta de açaí e extração do palmito, além da pesca em pequena escala. O extrativismo inserido na produção familiar tem sua importância significativa na permanência das pessoas no campo. Segundo Carraza (2010) e Mendes, Neves e Neves (2014), o extrativismo, além de fornecer uma diversidade de produtos oriundos da biodiversidade nativa, também auxilia a base econômica e social na preservação ambiental e melhoria da qualidade de vida dos ribeirinhos.

Em relação às atividades extrativistas na Ilha de Guajará de Baixo, segundo relatos dos moradores, o açaí é o produto de maior interesse da comunidade uma vez que agrega valor cultural, social e econômico na unidade de produção familiar e as atividades relacionadas com a produção dessa cultura dão-se basicamente durante o ano todo. Logo, a participação e o trabalho coletivo do núcleo familiar tornam-se fundamentais no decorrer dessa cadeia produtiva que envolve roçadores, apanhadores, debulhadores e amassadoras que extraem dele o "vinho"3.

No que se refere à composição familiar na comunidade, há em média 4,8 pessoas por família, que abrange crianças, adolescentes, jovens e adultos. As crianças e idosos são os responsáveis pelas atividades tidas como "leves" relacionadas à debulha do açaí, à coleta de frutos e à alimentação dos xerimbabos. Em contrapartida, os adultos executam os serviços "pesados" que envolvem todo o manejo das espécies na unidade de produção.

A idade média das mulheres participantes da pesquisa foi de 47 anos, mínima de 22 e máxima de 67 anos. Em relação ao estado civil, 78,6\% são amasiadas, $17,9 \%$ são casadas e 1,5\% é viúva. Para essas mulheres, o fato de viverem em união estável traz certa segurança e principalmente formaliza o companheirismo inclusive na realização das atividades produtivas que envolvem a família. Tal situação é corroborada por Ramos (2014) que afirma que a união estável concede às mulheres rurais maior reverência na comunidade, certa importância e representatividade social.

Sobre o nível de estudo, os percentuais indicam que 39\% das mulheres de Guajará de Baixo estudaram o ensino fundamental incompleto; $22 \%$ o fundamental completo; $14 \%$ o médio incompleto; $7 \%$ o médio completo, o superior completo ou não estudaram; e $4 \%$ possuem o ensino superior incompleto. Observou-se

Suco extraído do açaí in natura, que compõe a base alimentar das famílias ribeirinhas. É consumido diariamente preferencialmente acompanhado de farinha de mandioca, peixe e camarão. 
que o maior percentual de mulheres que não concluíram o ensino fundamental ou que não estudaram apresenta entre 45 e 67 anos.

Segundo Matos e Reis (2018), um dos impedimentos das mulheres ribeirinhas de concluírem os estudos é o fato de que, ao se amasiarem, acabam por destinar o seu tempo diário aos afazeres doméstico e materno, em conciliação com o trabalho na agricultura. Outros obstáculos como a carência de transporte, a disponibilidade de tempo, devido às múltiplas funções, o desânimo por se acharem com idade avançada e, principalmente, a falta de apoio dos maridos influenciam diretamente na dificuldade de conclusão dos estudos. Vale destacar que 68\% das mulheres entrevistadas alegaram que os maridos as impedem de ir à escola.

Para Ramos (2014), o elevado índice de mulheres que não concluíram os estudos pode implicar a questão da renda, visto que o baixo nível de escolaridade dificulta a busca por trabalhos formais. Essa realidade é percebida na comunidade, uma vez que nenhuma das entrevistadas possui emprego formal e nunca trabalhou tendo a carteira assinada.

A respeito dos afazeres diários das mulheres da Ilha de Guajará de Baixo, em relação à frequência relativa (\%), constatou-se que $61 \%$ do tempo diurno delas é dedicado aos cuidados da família, enquanto o restante do tempo, ou seja, $39 \%$, é destinado às atividades produtivas. Em ambos os casos, o que chama a atenção são as múltiplas tarefas desempenhadas diariamente pelas mulheres, tanto no âmbito produtivo quanto no reprodutivo.

Silva e Simonian (2006), ao estudarem as mulheres da várzea amazônica, verificaram que, apesar das múltiplas atividades produtivas realizadas pelas mulheres, ainda assim as atividades ligadas à dedicação familiar são as que ocupam a maior parte do tempo delas, principalmente as atividades destinadas à criação dos filhos e aos afazeres domésticos. Na Ilha de Guajará de Baixo, a realidade não se distingue daquela analisada pelas autoras. $\mathrm{Na}$ análise do tempo dedicado à família por essas mulheres, verificou-se que a maior parte deste é destinada aos afazeres domésticos (63\%) e o restante, ao repouso (18\%), participação religiosa $(15 \%)$ e recreação $(4 \%)$.

As mulheres entrevistadas afirmam que essas atividades que ocupam a maior parte de seu tempo têm relação, principalmente, com a criação dos filhos, como é possível verificar no trecho da entrevista a seguir:

Eu que faço o trabalho de casa [...]. Faço a boia, lavo as roupas sujas os pratos do almoço e da tarde [...]. Dou a boia dos meus filhos, do meu marido [...]. Tudinho isso eu faço [...]. Porque se eu não fazer, não tem quem faça por mim [...]. Não tenho pra quem pedir, eu mesma faço [...]. Depois da boia, a gente dorme um pouquinho aqui em casa [...]. Aí, tem 
dias que eu levo a minha família pra igreja [...]. Meus filhos gostam de ir no culto, lá eles cantam, tocam, aí eu os levo sempre que dá [...]. Nosso dia de lazer é no final de semana [...]. Tem uma praia que, de vez em quando, nós vamos dar uma voltinha lá [...]. (Informação verbal, mulheres da Ilha de Guajará de Baixo, 2018).

Quanto às atividades produtivas, “a mulher realiza na várzea atividades como a extração de frutos - com destaque para o açaí e para a pesca, sendo esta última realizada em pequena escala e envolvendo peixes e camarões" (SILVA; SIMONIAN, 2006, p. 9). Na Ilha de Guajará de Baixo, o tempo das mulheres destinado especificamente às atividades produtivas contempla o extrativismo do açaí, que corresponde a $43 \%$ do total. O restante deste tempo é distribuído entre atividade da pesca $(16 \%)$, artesanato $(13 \%)$, horticultura $(12 \%)$, coleta de sementes de oleaginosas (11\%) e criações de animais (5\%). Corroborando as reflexões de Rocha (2017), na Ilha de Guajará de Baixo, as mulheres ribeirinhas estão engajadas nas mais diversas atividades produtivas praticadas no estabelecimento familiar no meio rural.

A participação das mulheres de Guajará de Baixo nessas atividades garante o autoconsumo, assim como excedentes destinados à comercialização, exceto a pesca e os produtos da olericultura, que são destinados somente para consumo do núcleo familiar. Os trechos de entrevista abaixo revelam os detalhes dessas distintas funções desempenhadas pelas mulheres:

Aqui, de tudo eu faço um pouquinho [...]. Ajudo meu marido no açaizal, na pesca... consigo conciliar essas coisas [...]. Quando ele não tá aqui é eu com meu filho que faz [...]. Gasto muito meu tempo no açaizal [...]. Tempo de safra eu acordo cedinho aí eu e os menino vamos apanhar o açaí, enquanto o homem trabalha fora [...]. Fora de casa, a principal coisa que eu faço é apanhar o açaí pro vinho e pra vender [...]. Na pesca, a captura de camarão dá pra defender da boia, o peixe está cada dia mais difícil conseguir [...]. Tem a andiroba, a ucuuba que a gente ajunta as amêndoas e vende [...]. No finalzinho da tarde, teço meu paneiro [...]. O paneiro a gente usa pra pegar o camarão, botar o açaí [...]. Também cuido do porco, da galinha, do pato [...]. O açaí é a principal produção que a gente vende aqui do mato [...]. Uma vez por outra, vendo um pato, uma galinha [...]. Assim dá pra ganhar um dinheirinho pra ajudar na casa [...]. E assim a gente vai levando até quando Deus quiser [...]. (Informação verbal, mulheres da Ilha de Guajará de Baixo, 2018).

A partir dos relatos das mulheres, infere-se que a diversidade das atividades produtivas se constitui importante estratégia para a manutenção familiar. Os produtos oriundos dessas atividades asseguram a base alimentar da família e constituem fonte importante de renda (SILVA; HESPANHOL, 2016), que 
permite a aquisição de insumos não originados no estabelecimento familiar e de outros bens que proporcionam o bem-estar da família.

\section{AS "MULHERES DO AÇAÍ" E OS OBSTÁCULOS AINDA EXISTENTES À SUA AUTONOMIA}

Na Ilha de Guajará de Baixo, foram identificadas seis etapas na produção extrativista do açaí: limpeza do terreno (roçagem), manejo das espécies vegetais, apanha, debulha, carrega e comercialização (Figura 1). Cabe salientar que a distribuição dos afazeres por cada membro familiar nessas etapas é planejada pelo chefe da família ou pela necessidade de momento. Além do mais, o patriarca, "chefe da família", também detém o controle da unidade de produção na contratação de trabalhadores, na compra de insumos, nos contatos com os compradores e na administração em geral do estabelecimento (AMORIM; NADER, 2016).

Figura 1 - Algumas das etapas da produção extrativista de açaí: A) Debulha do açaí; B) Tecelagem de paneiro; C) Carrega do fruto açaí; D) Apanha de açaí com o uso do gancho; E) Comercialização via intermediário

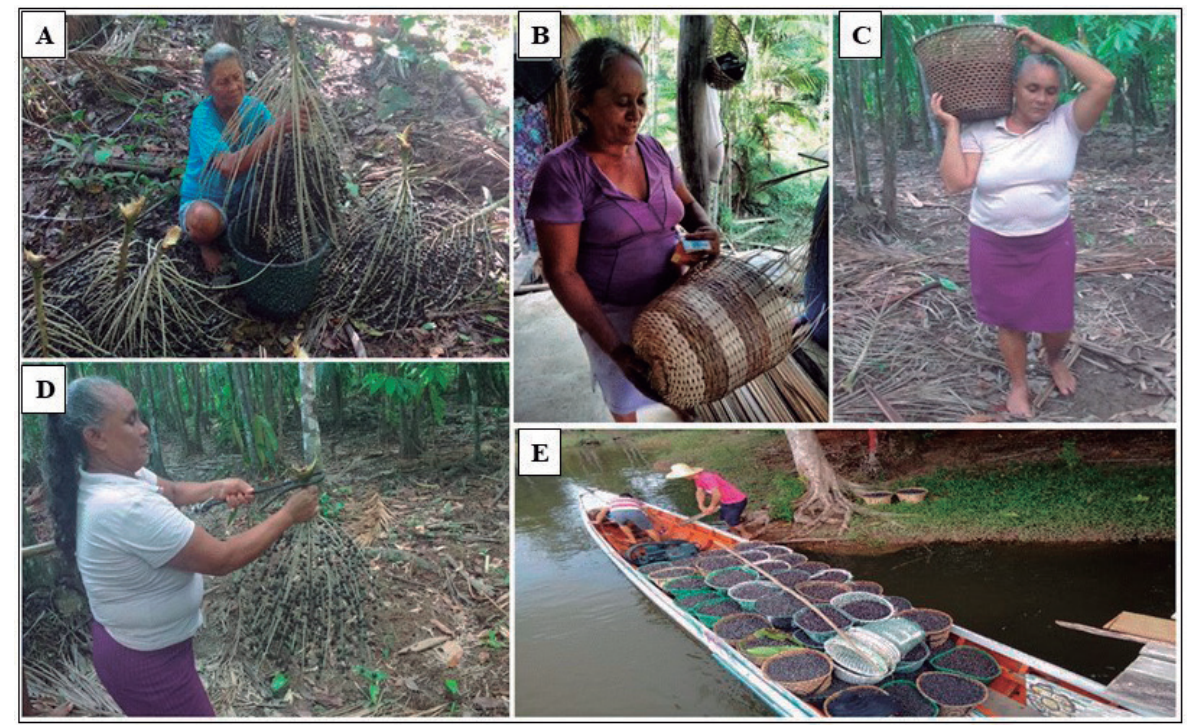

Fonte: elaboração dos autores, maio de 2018.

A seguir, são apresentadas as peculiaridades de cada uma dessas etapas, enfatizando como se dá o envolvimento feminino em cada uma delas: 
- Limpeza da área: refere-se à remoção das plantas espontâneas. Ocorre nos meses de junho, julho, dezembro e janeiro. Nas proximidades dos estabelecimentos, a limpeza do terreno é praticada com maior frequência pelas mulheres que manuseiam o terçado e a enxada para esta finalidade. Acerca dessa atividade, ao ser entrevistada, uma das mulheres menciona: "[...] de vez em quando, eu vejo que tá cerrado. Eu pulo aí pro terreiro com meu terçado pra cortar uns matos [...]. Lá pra capoeira é o homem que faz a limpeza do açaizal, minha responsabilidade fica aqui perto de casa [...]" (informação verbal) ${ }^{4}$;

- Manejo das espécies: configura-se como a etapa de realização de desbaste das touceiras e eliminação de árvores indesejadas. Nesta etapa, eliminam-se estipes mais altas, com injúrias físicas, improdutivos e adensados, deixando de três a cinco estipes por touceiras, assim como são subtraídas as árvores que sombreiam em excesso e que não despertam interesse dos agricultores. Esta prática predomina nos meses de fevereiro e março, após a limpeza do terreno. Terçados e machados são as principais ferramentas utilizadas no manejo. Como esta etapa exige maior esforço físico, as mulheres participam eventualmente, como revela a fala de uma entrevistada: "Depois que a gente roça, a gente vai cortar as açaizeiras mais altas, pra desabafar mais o açaizal e dar espaço para as novas [...]. Eu vou lá, carrego o palmito do mato, mas cortar, meu marido fala que é perigoso. E cansa mesmo, aí é ele com os filhos que corta [...]" (informação verbal) ${ }^{5}$.

- Apanha: realizada com a captura do cacho da copa do açaizeiro, o qual é trazido para a parte terrestre. Ocorre de duas formas, com os apetrechos peconha ${ }^{6}$ e gancho ${ }^{7}$. Com a utilização da peconha, o(a) peconheiro $(a)^{8}$ escala o estipe para alcançar o cacho e trazer até o debulhador. Com o gancho, o apanhador não necessita escalar o estipe, o cacho é puxado com o auxílio desse apetrecho. No que se refere a essa etapa, as mulheres mais idosas afirmam que sempre praticaram a apanha do açaí com a utilização da peconha, porém essa atividade se torna bastante cansativa. Após a invenção do gancho, tal etapa tornou-se menos fatigante.

- Debulha: nesse procedimento, de forma manual, o(a) debulhador(a) (ver Figura 1) realiza a retirada do fruto das ráquilas (pencas). Como recipiente para receber os frutos é utilizado o paneiro de tala de arumã. Os paneiros são confeccionados pelas mulheres, com formato e tecelagem artesanal. Para perdurar essa arte, as mulheres costumam ensinar aos filhos o passo a passo dessa técnica.

\footnotetext{
Informação fornecida por uma das mulheres da Ilha de Guajará de Baixo, em maio de 2018. Informação fornecida por uma das mulheres da Ilha de Guajará de Baixo, em maio de 2018.

6 Apetrecho que o(a) peconheiro(a) utiliza para dar sustento aos pés no ato de subir no açaizeiro. A peconha pode ser tecida da folha do açaizeiro ou de sacos de palhinha. Apetrecho feito com vergalhão, com uma envergadura na ponta que, amarrado a uma vara de bambu, atinge determinadas alturas para a captura do cacho de açaí.

8 Nome atribuído ao apanhador de açaí que faz uso da peconha para subir no açaizeiro.
} 
- Carrega: procede com o deslocamento da produção de onde foi colhido o fruto até o estabelecimento. Nesse trajeto, feito a pé, por dentro do açaizal, as mulheres colocam um paneiro por vez no ombro ou na cabeça até o destino. Um paneiro cheio de açaí pesa, em média, $15 \mathrm{~kg}$, fator este que dificulta às mulheres realizarem trajetos longos.

- Comercialização: compreende a etapa final, a qual se encerra com a venda do fruto. Na Ilha de Guajará de Baixo, as mulheres adotam dois fluxos de comercialização, via intermediários que se deslocam diariamente às residências para a compra da produção e/ou às feiras das vilas de Porto Grande e Carapajó. Nesta última opção, o valor de comercialização é superior ao pago pelos marreteiros. O açaí é vendido numa unidade de medida (lata) que corresponde a um paneiro cheio $(15 \mathrm{~kg})$. No que se refere a esta etapa, uma das entrevistadas alega: "Olha, eu vendo praticamente só pro marreteiro, porque ele vem buscar aqui no porto de casa e paga na hora também. Aí eu ganho tempo pra fazer outras coisas [...] de vez em quando, eu vendo na vila [...]. Na vila a vantagem é que o preço compensa [...]" (informação verbal)?.

A participação das mulheres é significativa em todas as etapas extrativistas do açaí, como verifica-se na Figura 2, a seguir.

Figura 2 - Participação total das mulheres nas etapas produtivas

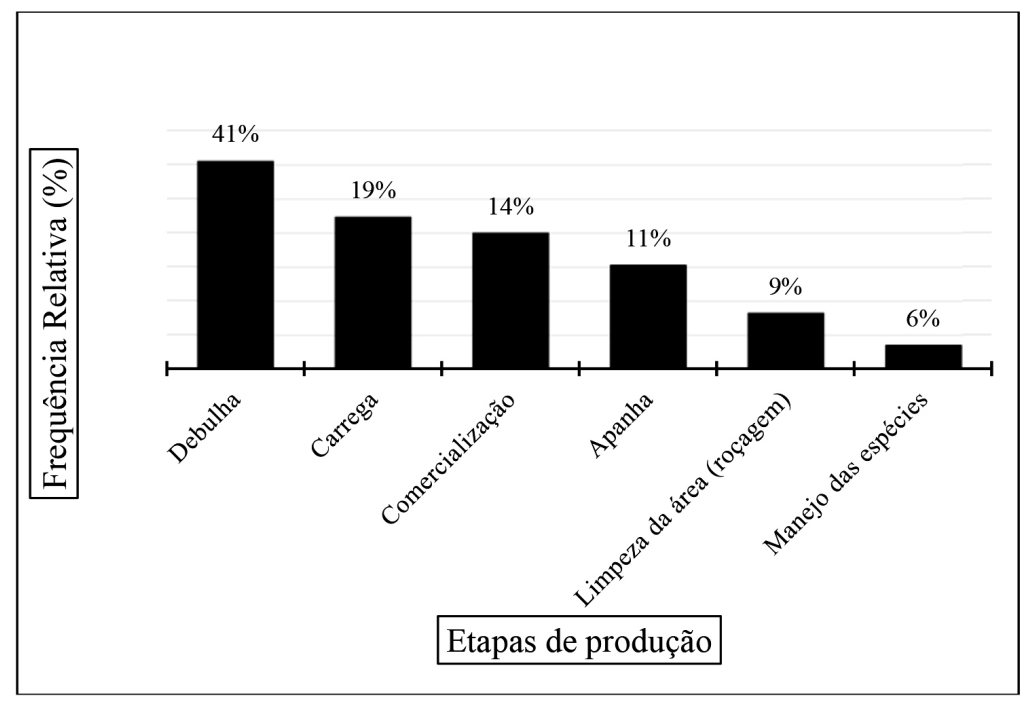

Fonte: elaboração dos autores, jul. 2021.

$\overline{9}$ Informação fornecida por uma das mulheres da Ilha de Guajará de Baixo, em maio de 2018. 
A debulha é a atividade desenvolvida por $41 \%$ das entrevistadas. No entanto, como mostrado na Figura 2, aproximadamente, 19\% participam da carrega do fruto. Já as que comercializam somam 14\%, e 11\% das mulheres também exercem a função de apanha. Além disso, 9\% delas praticam a limpeza da área (roçagem), e 6\% exercem o manejo das espécies. Esse envolvimento das mulheres não se restringe apenas ao extrativismo do açaí, abrange outras atividades no meio rural, o que atribui às mulheres rurais protagonismo relevante na geração de um leque diversificado de produtos destinados à subsistência da família (SILVA; SCHNEIDER, 2010).

Cabe salientar que, conforme as etapas produtivas do açaí exigem maior esforço físico, como o manejo do açaizal e a limpeza do terreno, a frequência relativa de participação das mulheres diminui (Figura 2). As entrevistadas alegam que os maridos poucas vezes as permitem realizar esse trabalho mais "pesado". De modo semelhante, Vieira, Rosa, Modesto e Santos (2008) também verificaram esta situação ao estudarem a relação entre gênero e sistema agroflorestal (SAF), no município de Igarapé Açu (PA). Os autores constataram que, apesar das mulheres desempenharem várias atividades em SAF, elas consideram pouca a participação nos trabalhos produtivos "pesados".

Segundo as mulheres de Guajará de Baixo, há aproximadamente quatro anos, a apanha era praticada exclusivamente com a utilização da peconha. Entretanto, com a invenção do gancho, a apanha com a peconha vem aos poucos sendo substituída fato este comprovado nesta pesquisa, na qual $80 \%$ das mulheres entrevistadas praticam a apanha com o auxílio do gancho, por considerar mais prático e menos cansativo do que com o uso da peconha, que ainda é utilizada por $20 \%$ das mulheres.

O elevado índice participativo das mulheres da Ilha de Guajará de Baixo na etapa de comercialização se dá em função da venda diretamente aos atravessadores, que representa $82 \%$ dos casos, pois a comercialização é realizada no próprio estabelecimento. O preço pago pelos atravessadores na lata do açaí é sempre inferior ao esperado pelas famílias, pois os atravessadores usufruem da estratégia de tabelar o preço pago por lata (CORRÊEA, 2016).

Quando comercializado na feira das vilas, o valor ofertado é em torno de $20 \%$ superior ao oferecido pelos atravessadores. Contudo, é exigido dos agricultores disponibilidade de tempo, despesa com combustível e esforço físico para carregar o paneiro até o local de comercialização. Ademais, nessa modalidade de venda, há a incerteza de não vender o produto. Logo, as mulheres veem tal fluxo de comercialização como desvantajoso, principalmente porque elas também usufruem do tempo para a realização de outras atividades ligadas à produção e à dedicação familiar. 
Apesar do esforço dispensado pelas mulheres em todas as etapas na produção extrativista do açaí, a maior parte do valor arrecadado na comercialização é destinada ao "chefe da família". Para Matos e Reis (2018), na cultura patriarcal, tal fato acontece por o chefe da família ser visto como o provedor do lar.

As mulheres consideram isso habitual, pois o homem é o responsável por comprar as coisas "pra dentro da casa" (comida, combustível, despesas etc.). Eventualmente, quando se necessita comprar um sapato ou uma roupa, as mulheres recebem um valor mais elevado dos maridos com a venda do açaí. Entretanto, do baixo valor que é destinado a elas, uma das prioridades é investir nos filhos, conforme mostra a descrição abaixo:

O dinheiro da venda é o marido que fica [...]. Aqui em casa é o chefe da família que fica com o dinheiro da venda [...]. Ele é o responsável pela casa, então o dinheiro tem que ficar com ele [...]. Ele sabe o que faz com o dinheiro [...]. Quando eu preciso, ele me dá uma pontinha, aí eu compro meu sapato, minha roupa, mas é mais tempo de festa [...]. Do pouco que ele me dá, eu compro o material da escola do meu filho, a roupa dele [...]. Meus filhos também precisam comprar as coisas deles, aí do pouco que ganho, eu o ajudo [...] E assim a gente vai levando [...] (Informação verbal, mulheres da Ilha de Guajará de Baixo, 2018).

Nas entrevistas se torna explícita a insegurança em lidar com a parte financeira. Elas alegam que preferem que fique incumbida ao marido essa função, por ser do "chefe da família" a responsabilidade de administrar os recursos financeiros da casa.

A pesquisa de Vieira, Rosa, Modesto e Santos (2008) também identifica o marido como encarregado da administração dos recursos na unidade produtiva, inclusive do dinheiro. Nas investigações de Brumer (2004), acerca das relações de gênero no meio rural, verificou-se que a tomada de decisão é conduzida pelo homem, sendo o mesmo encarregado pelos recursos provenientes da agricultura. Georgin et al. (2015), por outro lado, acrescentam que, nos últimos anos, houve aumento de tomadas de decisões por parte de mulheres, mesmo que o controle financeiro ainda seja privilégio do marido.

As pesquisas mencionadas corroboram o seguinte aspecto: a insegurança tem sido a principal causa da baixa participação da mulher na etapa decisória. Essa insegurança, por sua vez, é avultada pelos discursos patriarcais de que os homens, chefes de família, são os detentores das capacidades necessárias a esta função. Esse obstáculo à construção de autonomia feminina ainda é significativo em todas as unidades produtivas às quais vinculam-se as entrevistadas dessa comunidade. 
Quase 80\% das mulheres da Ilha de Guajará de Baixo participam de mais de uma atividade relacionada ao extrativismo do açaí. A debulha e a carrega são etapas interligadas e aparecem em maior frequência de participação. De acordo com o que foi relatado, as mulheres responsáveis pela debulha também exercem a função de carrega, principalmente quando a colheita do açaí se dá nos quintais da propriedade. Em vista disso, a frequência de participação das mulheres nas etapas de produção é constituída conforme destaca a Tabela 1.

Tabela 1 - Número de mulheres envolvidas nas etapas produtivas do açaí

\begin{tabular}{|c|c|c|c|}
\hline & Etapas & $\begin{array}{c}\mathrm{N}^{\mathrm{o}} \text { de } \\
\text { participação }\end{array}$ & $\operatorname{Fr}(\%)$ \\
\hline 1 & Debulha + Carrega & 14 & $29 \%$ \\
\hline 2 & Comercializa + Carrega & 6 & $13 \%$ \\
\hline 3 & Comercializa + Apanha & 4 & $8 \%$ \\
\hline 4 & Comercializa & 4 & $8 \%$ \\
\hline 5 & Debulha & 4 & $8 \%$ \\
\hline 6 & Apanha + Debulha & 4 & $8 \%$ \\
\hline 7 & Limpeza do terreno + Debulha & 2 & $4 \%$ \\
\hline 8 & Apanha & 2 & $4 \%$ \\
\hline 9 & Debulha + Carrega + Apanha & 2 & $4 \%$ \\
\hline 10 & Manejo do açaizal + Debulha & 2 & $4 \%$ \\
\hline 11 & $\begin{array}{l}\text { Limpeza do terreno }+ \text { Debulha }+ \text { Carrega }+ \\
\text { Comercializa }\end{array}$ & 1 & $2 \%$ \\
\hline 12 & Debulha + Carrega + Comercializa & 1 & $2 \%$ \\
\hline 13 & $\begin{array}{l}\text { Limpeza do terreno }+ \text { Apanha }+ \text { Debulha }+ \\
\text { Carrega }\end{array}$ & 1 & $2 \%$ \\
\hline 14 & $\begin{array}{l}\text { Manejo do açaizal }+ \text { Limpeza do terreno }+ \\
\text { Apanha }+ \text { Comercializa }+ \text { Carrega }+ \text { Debulha }\end{array}$ & 1 & $2 \%$ \\
\hline
\end{tabular}

Fonte: elaboração dos autores, jul. 2021.

Apesar da participação das mulheres ser fundamental em todas essas etapas, ainda assim, elas próprias consideram que os afazeres desenvolvidos em relação à produção não se configuram como trabalho, apenas como "ajuda" ao marido. No entanto, somente os afazeres domésticos são considerados por elas como trabalho, constatação esta que vai ao encontro das reflexões de Schmitz e Santos (2013) sobre a desvalorização das atividades femininas pela família, sendo estas compreendidas como ajuda. 
Mesquita e Mendes (2012) também constataram a desvalorização do trabalho desempenhado pelas mulheres de Rancharia (GO) em relação à produção. As autoras afirmam que, muitas vezes, a mulher tem jornada de trabalho superior à do homem, conciliando atividades domésticas e agrícolas, mas este tipo de trabalho ainda assim é considerado apenas como "ajuda", tendo em vista que não gera valor econômico e/ou social. Em contrapartida, ao analisarmos essa situação na localidade em estudo, além do trabalho praticado pelas mulheres gerar renda, o zelo pela família e o trabalho coletivo influenciam a reprodução socioeconômica da família.

Ao estudarem mulheres no semiárido brasileiro, Rios, Bastos e Barros (2015) constataram que o trabalho desenvolvido por elas também é marcado pela invisibilização. Apesar de todas participarem ativamente na agricultura, ao serem questionadas sobre seu trabalho, muitas delas afirmam que não trabalham, pois os afazeres desenvolvidos por elas são voltados aos cuidados familiares e não geram renda.

De modo geral, a falta de participação das mulheres em reuniões comunitárias, associações e cooperativas também contribui para a invisibilidade de seu trabalho em relação à sociedade, distanciando-as, consequentemente, do empoderamento feminino. Na comunidade de Guajará de Baixo, a participação das mulheres em organizações coletivas se dá apenas eventualmente em cultos e celebrações religiosas. Ainda que $63 \%$ das mulheres sejam associadas à Colônia de Pescadores Z-16 de Cametá (PA), situada na sede do município, as mulheres afirmaram que as únicas vantagens alcançadas em estarem associadas a essa entidade é o recebimento do seguro defeso ${ }^{10}$, correspondente a quatro saláriosmínimos, e o direito à representação previdenciária mediante o pagamento de uma taxa que serve para a aposentadoria por idade.

Nesse contexto, verifica-se a fragilidade não somente das mulheres, mas também da comunidade em geral, em relação à organização coletiva. Essa fragilidade acaba por limitar o acesso a novos mercados, a programas governamentais e a melhores preços para a comercialização, principalmente da produção extrativista do açaí. Na agricultura familiar, a organização em dispositivos coletivos dos agricultores torna-se uma oportunidade para se conseguir a agregação de valor e acesso a novos mercados, além da facilidade de construção de novos conhecimentos e da superação de desafios que se apresentam.

Estudos realizados por Salvaro, Estevam e Felipe (2014) sobre a participação das mulheres em organizações coletivas mostram ganhos profissionais em termos

${ }_{10}$ Seguro Defeso é um benefício pago ao pescador artesanal, que fica proibido de exercer a atividade pesqueira durante o período de defeso de alguma espécie. 
de autonomia e liberdade, visibilidade e reconhecimento do trabalho, interação social, trabalho prazeroso e renda proveniente da comercialização. Decorrente disso, essas mulheres adquirem conhecimentos em administração e gerenciamento, sentem-se mais seguras para lidar com dinheiro e detêm maior liberdade de tomada de decisão, o que irradia também consequências ao seu empoderamento.

Vale mencionar que essas transformações estabelecem-se por meio de um processo contínuo, no qual as próprias mulheres se tornam protagonistas e rompem com o paradigma machista imposto ao longo da história. Com isso, a mulher tem maiores oportunidades de seu trabalho ser valorizado e supera o rótulo de sexo frágil (VIEIRA; ROSA; MODESTO; SANTOS, 2008). Assim como em outros contextos amazônicos, na Ilha de Guajará de Baixo, a organização social se coloca como potencial instrumento de transformação do desenvolvimento rural e de inclusão social. Nesse sentido, compreender quais fatores catalisam estratégias de organização social capazes de fortalecer a visibilização do trabalho feminino no campo, bem como estimular o envolvimento das mulheres mais jovens em dispositivos coletivos emergentes nos contextos amazônicos, parece salutar.

\section{CONSIDERAÇÕES FINAIS}

O cotidiano das mulheres ribeirinhas da Ilha Guajará de Baixo, desde as primeiras horas do dia até ao anoitecer, é marcado pela atuação em múltiplas atividades produtivas e reprodutivas. Essas mulheres, que possuem os mais variados perfis, como curandeiras, benzedeiras, parteiras, pescadoras, extrativistas etc., são vitimadas pelo não reconhecimento de seus trabalhos, que perpassa pela esfera familiar e atinge o nível social, cultural e político. Nessa investigação que envolveu diretamente 28 mulheres fica evidente que estas assumem a responsabilidade pelo trabalho reprodutivo, constituído pelo zelo com o lar e com o núcleo familiar, e produtivo, engajando-se em todas as etapas relativas aos cuidados com o açaí: na limpeza do terreno, ou roçagem, no manejo das espécies vegetais, na apanha, na debulha, na carrega e na comercialização. Envolvendo-se com maior expressividade na debulha, momento no qual a retirada dos frutos das pencas é realizada por suas próprias mãos e estes são colocados em paneiros confeccionados de tala de arumã, os quais são tecidos também por essas mesmas mãos femininas. $\mathrm{Na}$ ausência do marido, inclusive, essas mulheres assumem sozinhas, ou em companhia dos filhos, todas essas etapas. No entanto, as mulheres ainda têm pouca participação na administração financeira e na tomada de decisão das práticas produtivas familiares, convivendo com a invisibilização de seu trabalho. 
Embora todos esses afazeres sejam essenciais para a família, a cultura do patriarcado no meio rural ainda irradia consequências no que se refere ao desprezo acerca do trabalho feminino, produtivo e reprodutivo. Frente a esta situação, percebe-se a potencialidade da organização coletiva, que inclusive já envolve algumas mulheres ribeirinhas. No entanto, um dispositivo coletivo que poderia se materializar como instrumento potencializador de autonomia e empoderamento feminino no campo, que é a Colônia de Pescadores, ainda está distante de alcançar o rompimento com a desigualdade de gênero. Por mais importante que essa organização seja na operacionalização do seguro defeso, as mulheres argumentam que sua atuação fica restrita a esse propósito.

De modo geral, os discursos dessas 'mulheres do açaî', que possuem importância profunda em todas as atividades reprodutivas do núcleo familiar, mas, sobretudo, nas atividades produtivas vinculadas ao açaí, evidenciam suas ligações incontestáveis com o meio biofísico. Tais ligações se materializam em estratégias tanto de garantia da segurança alimentar e nutricional de suas famílias quanto da renda para sua reprodução socioeconômica. Essa pesquisa em questão abre janelas de oportunidade para estudos futuros que possam abarcar com maior profundidade, por exemplo, a questão geracional no seio dessa discussão sobre o trabalho feminino no campo. Afinal, se mostra significativo compreender como as jovens ribeirinhas do Baixo Tocantins vem concebendo suas percepções acerca do espaço rural e como essas percepções culminam em decisões e modificações em suas trajetórias de vida e na própria configuração dos projetos de desenvolvimento rural nesse território.

\section{REFERÊNCIAS}

\section{AMARAL, W. R. S. No vai e vem das marés, o movimento da vida:}

mulheres, família e trabalho na Ilha de Quianduba, Abaetetuba/PA. 2016. 240 f. Tese (Doutorado em Sociologia) - Programa de Pós-Graduação em Sociologia e Antropologia, Universidade Federal do Pará, Belém, 2016.

AMORIM, E. O.; NADER, M. B. Mulher e trabalho: como o patriarcado determina a invisibilidade da mulher no meio rural. In: ENCONTRO INTERNACIONAL DE ESTUDOS DE GÊNERO, 2., 2016, Vitória. Anais [...]. Vitória: UFES, 2016. p. 1-11.

\section{BATISTA, K. T. Avaliação da sustentabilidade de agroecossistemas} familiares agroextrativistas de açaizeiros na região das ilhas do município de Cametá, Pará. 2013. 155 f. Dissertação (Mestrado em Agriculturas Familiares e Desenvolvimento Sustentável) - Programa de Pós-Graduação em Agriculturas Amazônicas, Universidade Federal do Pará, Belém, 2013. 
BATISTA, K. T.; SANTANA, A. C.; LEMOS, W. D. P. Fatores determinantes da sustentabilidade em agroecossistemas agroextrativistas de açaizeiros na região das ilhas do município de Cametá, Pará. Amazônia: ciência \& desenvolvimento, Belém, v. 12, n. 22, p. 65-77, jan./jun. 2016.

BATISTA, S. S. M. O modo de viver como um instrumento de resistência do saber popular dos moradores da Ilha do Combu, Belém-Pará. 2010. 115 f. Dissertação (Mestrado em Serviço Social) - Programa de Pós-Graduação em Serviço Social, Universidade Federal do Pará, Belém, 2010.

BRUMER, A. Gênero e agricultura: a situação da mulher na agricultura do Rio Grande do Sul. Estudos Feministas, Florianópolis, v. 12, n. 1, p. 205-227, 2004. BURG, I. C.; LOVATO, P. E. Agricultura familiar, agroecologia e relações de gênero. Cadernos de Agroecologia, [s. l.], v. 2, n. 1, p. 1522-1528, 2007.

CARRAZZA, L. R. Produção e comercialização de produtos agroextrativistas do Cerrado no PPP-Ecos: avanços, limites e desafios. In: LOBO, A.; FIGUEIREDO, I.; ANDRADE, K. (org.). Sementes lançadas, frutos colhidos: o Programa de Pequenos Projetos Ecossociais. Brasília: ISPN, 2010. p. 87-109.

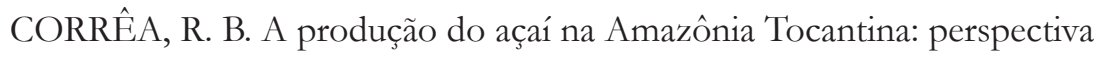
para o desenvolvimento regional. In: ENCONTRO NACIONAL DE GEÓGRAFOS, 18., 2016, São Luís. Anais [...]. São Luís: UFMA, 2016. p. 1-12. COSTA, G. K. G. Cametá: interações cidade-rio na orla fluvial de um núcleo urbano ribeirinho do Baixo Tocantins. Belém: PROPESP/UFPA, 2010. (Relatório de pesquisa).

CRESWELL, J. W. Projeto de pesquisa: métodos qualitativo, quantitativo e misto. Porto Alegre: Artmed, 2007.

FARIA, N.; NOBRE, M. Gênero e desigualdade. In: FARIA, N.; NOBRE, M. Gênero e desigualdade. São Paulo: Editora SOF, 1997. p. 51-71.

GEORGIN, J. et al. A participação feminina na agricultura agroecológica: um estudo do caso na região norte do Rio Grande do Sul. Revista Monografias Ambientais, Santa Maria, RS, v. 14, n. 3, p. 01-09, 2015.

GIL, A. C. Métodos e técnicas de pesquisa social. 6. ed. São Paulo: Editora Atlas, 2008.

GORES, J. Agroecologia, relações produtivas e de gênero na agricultura familiar: o estudo de caso da associação de produtores agroecológicos sementes do futuro de Atalanta-SC. Ágora, Vitória, v. 17, n. 2, p. 131-143, 2015. 
HERRERA, K. M. Uma análise do trabalho da mulher rural através da perspectiva da multifuncionalidade agrícola. In: SEMINÁRIO INTERNACIONAL FAZENDO GÊNERO, 10, 2013, Florianópolis. Anais [...]. Florianópolis: UFSC, 2013. p. 1-12.

IBGE. Pesquisa Agrícola Municipal. IBGE, Rio de Janeiro, 2019. Disponível em: https://sidra.ibge.gov.br/pesquisa/pam. Acesso em: 10 jul. 2021.

LEFEVRE, F.; LEFEVRE, A. M. C. O discurso do sujeito coletivo: um novo enfoque em pesquisa qualitativa. Caxias do Sul: Educs, 2003.

MATOS, C. C.; REIS, M. E. Educação de mulheres ribeirinhas no município de Breves. Revista Brasileira de Educação do Campo, Palmas, v. 3, n. 4, p. 1249-1267, 2018.

MENDES, M. F; NEVES, S. M. A. S.; NEVES, R. J. A experiência das mulheres extrativistas do assentamento Margarida Alves em Mirassol d'Oeste/MT.

Geografia em Questão, Marechal Cândido Rondon, v. 7, n. 1, p. 34-49, 2014.

MESQUITA, L. A. P.; MENDES, E. P. P. Mulheres na agricultura familiar: a comunidade Rancharia, Campo Alegre de Goiás (GO). In: ENCONTRO NACIONAL DE GEOGRAFIA AGRÁRIA, 21., 2012, Uberlândia. Anais [...]. Uberlândia: UFU, 2012. p. 1-20.

NOBRE, M. Relações de gênero e agricultura familiar: gênero e agricultura familiar. São Paulo: Sempreviva Organização Feminista, 1998.

OLIVEIRA, T. N.; BRANDÃO, L. P.; PENA, H. W. A. et al. Análise da dinâmica da estrutura produtiva do município de Cametá, Amazônia-Brasil. Observatorio de la Economía Latinoamericana, [s. l.], 2014. Disponível em: https://www.eumed.net/cursecon/ecolat/br/14/economia-cameta.html. Acesso em: 04 ago. 2021.

RAMOS, C. P. Mulheres rurais atuando no fortalecimento da agricultura familiar local. Revista Gênero, Niterói, v. 15, n. 1, p. 29-46, 2014.

RIOS, P. P. S.; BASTOS, A. S.; BARROS, E. R. Mulheres no semiárido brasileiro: uma história invisibilizada. Revista Ouricuri, Juazeiro, v. 5, n. 2, p. 1-17, 2015.

ROCHA, V. O. A importância das questões de gênero no âmbito rural: as múltiplas atividades desenvolvidas por mulheres na zona rural do município de Manaus/ Amazonas. In: SEMINÁRIO INTERNACIONAL FAZENDO GÊENRO, 11.; WOMEN'S WORLDS CONGRESS, 13., 2017, Florianópolis. Anais [...]. Florianópolis: UFSC, 2017. p. 1-9. 


\section{ROCHA, V. O. O protagonismo das mulheres agricultoras do}

Assentamento Água Branca: trajetória de trabalho e organização social em Manaus-Amazonas. 2019. 146 f. Dissertação (Mestrado em Serviço Social) - Programa de Pós-Graduação em Serviço Social, Universidade Federal do Amazonas, Manaus, 2019.

RODRIGUES, D. C. B.; ANDRADE, N. T.; SILVA, T. S.; NASCIMENTO, C. F. P. Organização e trabalho das mulheres ribeirinhas amazônicas: um estudo nas comunidades de Santa Luzia e São Lázaro no Grande Lago de Manacapuru/AM. Retratos de Assentamentos, Araraquara, v. 18, n. 1, p. 113-134, 2015.

SALVARO, G. I. J.; ESTEVAM, D. O.; FELIPE, D. F. Mulheres em cooperativas rurais virtuais: reflexões sobre gênero e subjetividade. Psicologia: ciência e profissão, [s. l.], v. 34, p. 390-405, 2014.

SANTANA, A. C.; PESSOA, J. D. C.; SANTANA, A. L. O mercado de açaí e os desafios tecnológicos da Amazônia. In: PESSOA, J. D. C. e TEIXEIRA, G. H. A. (ed.). Tecnologias para inovação nas cadeias euterpe. Brasília, DF: Embrapa, 2012. p. 21-40.

SANTOS, J. B.; BOHN, L.; ALMEIDA, H. J. F. O papel da mulher na agricultura familiar de Concórdia (SC): o tempo de trabalho entre atividades produtivas e reprodutivas. Textos de Economia, Florianópolis, v. 23, n. 1, p. 1-27, 2020.

SCHMITZ, A. M.; SANTOS, R. A. A divisão sexual do trabalho na agricultura familiar. In: SEMINÁRIO INTERNACIONAL FAZENDO GÊNERO, 10., 2013, Florianópolis. Anais [...]. Florianópolis: UFSC, 2013. p. 1-10.

SCHNEIDER, S. A pluriatividade como estratégia de reprodução social da agricultura familiar no Sul do Brasil. Estudos Sociedade e Agricultura, Seropédica, RJ, n. 16, p. 164-184, 2001.

SILVA, A. A.; STEWARD, A. M. A valorização do trabalho das mulheres na comunidade do Igarapé Combu, Ilha do Combu-Pará. Agricultura Familiar: pesquisa, formação e desenvolvimento, Belém, v. 13, n. 2, p. 208-229, 2020. SILVA, C. B. C.; SCHNEIDER, S. Gênero, trabalho rural e pluriatividade. In: SCOT'T, P.; CORDEIRO, R.; MENEZES, M. (org.). Gênero e geração em contextos rurais. Ilha de Santa Catarina: Ed. Mulheres, 2010. p. 183-208. SILVA, C. N.; SIMONIAN, L. T. L. A questão de gênero: um breve estudo no estuário amazônico. Papers do NAEA, Belém, v. 1, p. 1-17, 2006. 
SILVA, J. M.; HESPANHOL, R. A. M. As estratégias de reprodução social dos agricultores familiares das comunidades rurais do município de Catalão (GO). Geo UERJ, Rio de Janeiro, n. 29, p. 402-430, 2016.

SILVA, M. R. Gênero, desigualdades e agricultura: a mulher na atividade agrícola familiar. Brazilian Journal of Development, [s. l.], v. 5, n. 3, p. 2095-2105, 2019. SIMONIAN, L. T. L. Pescadoras de camarão: gênero, mobilização e sustentabilidade na ilha Trambioca, Barcarena, Pará. Boletim do Museu Paraense Emílio Goeldi. Ciências Humanas, Belém, v. 1, p. 35-52, 2006. VIEIRA, T. A.; ROSA, L. S.; MODESTO, R. S; SANTOS, M. M. Gênero e sistemas agroflorestais: o caso de Igarapé-Açu, Pará, Brasil. Revista de Ciências Agrárias, Belém, v. 50, n. 1, p. 143-154, 2008. 